\title{
EFEKTIVITAS PENGAJARAN MIKRO BERBASIS BLENDED LEARNING BAGI MAHASISWA CALON GURU MATEMATIKA
}

\author{
Kurnia Putri Sepdikasari Dirgantoro', Robert Harry Soesanto 2 \\ 1,2 Universitas Pelita Harapan, JI. MH. Thamrin Boulevard 1100 Lippo Village, Tangerang, Indonesia \\ Email: 1kurnia.dirgantoro@uph.edu, 2robert.soesanto@uph.edu
}

\begin{abstract}
The current pandemic situation allows no possibility for face-to-face learning activities. Learning activities must also be carried out online. Therefore, teachers need to continue to train and develop themselves to be ready to face the existing changes. Students as prospective teachers must also be carefully prepared. One way is through microteaching. This research was conducted to see the effectiveness of online microteaching based on blended learning. The research subjects included 35 students of level 3 mathematics education study program. This research is descriptive qualitative research using instruments such as microteaching rubrics, questionnaires, and written interviews regarding the effectiveness of microteaching. The study concludes that online microteaching based on blended learning (synchronous and asynchronous) is still considered effective in developing student-teacher teaching skills. This was obtained based on the analysis of research instruments (microteaching results rubric, rubric, and written interviews). They learn how to prepare interesting (help students enjoy the learning process) and quality blended learning (achieve the learning objectives) strategies, media, and learning for students.
\end{abstract}

Keywords: Blended learning, online, microteaching, synchronous-asynchronous

\begin{abstract}
ABSTRAK
Situasi pandemi saat ini tidak memungkinkan kegiatan pembelajaran dilaksanakan secara tatap muka. Kegiatan pembelajaran harus dilaksanakan secara daring. Oleh karenanya guru perlu terus melatih dan mengembangkan dirinya untuk siap menghadapi perubahan yang ada. Mahasiswa sebagai calon guru harus dipersiapkan secara matang. Salah satu caranya adalah melalui pengajaran mikro. Penelitian ini dilaksanakan untuk melihat efektivitas pengajaran mikro secara daring yang dilaksanakan berbasis blended learning. Subjek penelitian meliputi 35 mahasiswa tingkat 3 prodi pendidikan matematika. Penelitian ini merupakan penelitian kualitatif deskriptif dengan menggunakan instrumen yang meliputi: rubrik pengajaran mikro, kuesioner, dan wawancara tertulis mengenai efektivitas pengajaran mikro. Kesimpulan yang diperoleh adalah pengajaran mikro secara daring berbasis blended learning (sinkronus dan asinkronus) dinilai masih efektif dalam mengembangkan keterampilan mengajar mahasiswa calon guru. Hal ini diperoleh berdasarkan analisis instrumen penelitian (rubrik hasil pengajaran mikro, rubrik, dan wawancara tertulis). Mahasiswa calon guru belajar bagaimana mempersiapkan strategi, media, dan pembelajaran blended learning yang menarik (membantu siswa menikmati proses pembelajaran) dan berkualitas (memenuhi tujuan pembelajaran) bagi siswa.
\end{abstract}

Kata kunci: Blended learning, daring, pengajaran mikro, sinkronus-asinkronus

Dikirim: 27 Februari 2021; Diterima: 31 Agustus 2021; Dipublikasikan: 30 September 2021

Cara sitasi: Dirgantoro, K. P. S., \& Soesanto, R. H. (2021). Efektivitas pengajaran mikro berbasis blended learning bagi mahasiswa calon guru matematika. Teorema: Teori dan Riset Matematika, 6(2), 139-149. DOI: http://dx.doi.org/10.25157/teorema.v6i2.5088 


\section{PENDAHULUAN}

Pandemi Covid-19 yang terjadi mulai Maret 2020 mengubah berbagai segi kehidupan, termasuk dalam bidang pendidikan. Para pendidik merasa perlu menyusun lingkungan baru agar pembelajaran tetap kontinu (Bakker \& Wagner, 2020), sehingga berbagai upaya dilakukan untuk menjamin keberlangsungan interaksi antara pendidik dengan peserta didik. Proses pembelajaran pada konteks sekolah maupun universitas tidak lagi terjadi dalam ruang kelas konvensional, melainkan dalam format kelas daring dengan menggunakan berbagai platform yang cukup populer seperti Zoom (Monica \& Fitriawati, 2020; Ismawati \& Prasetyo, 2020), Microsoft Teams (Nugroho, 2021; Fahmi, 2020), maupun Google Classroom (Yulyani, 2020). Desain pembelajaran daring yang tergolong umum dilakukan adalah desain blended learning, dimana melibatkan kombinasi antara aktivitas tatap muka (face-to-face) dengan mengintegrasikan penerapan teknologi melalui berbagai sumber maupun platform digital (Rasheed et al., 2020; Porter et al., 2014). Pada konteks pandemi saat ini, blended learning dapat dilakukan dengan memanfaatkan koneksi internet untuk menghubungkan pendidik dengan peserta didik melalui pertemuan sinkronus dan mengkombinasikannya dengan aktivitas asinkronus (Dhawan, 2020).

Desain pembelajaran blended learning sudah diterapkan di dalam dunia pendidikan, bahkan sebelum eksistensi pandemi berlangsung. Wichadee (2017) menyatakan bahwa blended learning dapat mereduksi defisiensi yang ditemukan pada proses pembelajaran tatap muka yang memiliki keterbatasan waktu dalam pengajaran. Sejumlah penelitian terdahulu juga mengungkapkan adanya hasil positif dari blended learning terhadap prestasi maupun hasil belajar dari peserta didik. Penelitian yang dilakukan oleh Jou et al., (2016) pada konteks perguruan tinggi memberikan temuan terkait kemampuan berpikir kritis mahasiswa yang meningkat sebagai dampak diterapkannya blended learning sebagai model pembelajaran. Temuan lain yang dihasilkan adalah adanya peningkatan motivasi dalam belajar dikarenakan lingkungan pembelajaran yang inovatif. Selain itu, terdapat juga penelitian dari Woltering et al., (2009) yang memberikan temuan positif terkait kepuasan mahasiswa serta kemandirian belajar yang diperoleh melalui penerapan blended learning dengan mengintegrasikan pertemuan tatap muka disertai pemanfaatan modul digital.

Secara kontras, di balik temuan positif dalam relevansinya dengan blended learning ini, terdapat juga beberapa tantangan yang harus dihadapi baik sebagai pendidik maupun peserta didik. Studi yang dilakukan Muhazir \& Retnawati (2020) memaparkan mengenai beberapa tantangan yang dihadapi oleh guru sekolah dalam mengimplementasikan teknologi ke dalam blended learning yang meliputi kecakapan guru terhadap penggunaan teknologi itu sendiri serta masalah fasilitas dan infrastruktur pada instansi pendidikan yang belum memadai. Hal yang sama juga dialami oleh pendidikan di tingkat universitas. Sebuah survei yang dilakukan oleh Herliana et al., (2020) memberikan temuan mengenai ketidaksiapan dosen ketika menjalankan blended learning dikarenakan belum terbiasa terlibat aktif dalam mengakses internet maupun platform pembelajaran ke dalam aktivitas perkuliahan. Selain itu, perihal kecakapan dosen terhadap kemampuan penggunaan platform pembelajaran juga ditemukan pada survey tersebut. Sebanyak $46,16 \%$ dosen mengalami kesulitan dalam beradaptasi dengan konteks pembelajaran daring yang menuntut penguasaan teknologi secara optimal.

Tantangan blended learning juga dihadapi oleh peserta didik sebagai pembelajar di tengah konteks pembelajaran daring ini. Studi kualitatif deskriptif yang dilakukan oleh Manurung et al., (2020) terhadap tiga kategori pembelajar (tinggi, sedang, rendah) pada sebuah universitas di Palu memaparkan hasil persepsi terkait implementasi blended learning terhadap ketiga kategori. Pada kategori rendah, mahasiswa meyakini bahwa blended learning memberikan nuansa pembelajaran yang bermakna namun terkendala dengan penguasaan teknologi yang perlu untuk terus dikembangkan. Sementara itu, pembelajar dengan kategori sedang dan tinggi meyakini bahwa blended learning memberikan pengalaman belajar yang seru dan mengasyikan. Namun bukan berarti tidak ada tantangan yang dihadapi. Secara umum, tantangan berupa kendala teknis seperti stabilitas konektivitas internet dialami oleh ketiga kategori pembelajar, dimana hal tersebut mengakibatkan proses pembelajaran daring menjadi tidak optimal. Selain itu, kecakapan dalam penguasaan teknologi juga tidak merata pada setiap mahasiswa, sehingga kondisi ini memerlukan berbagai ide serta pemikiran dari para peneliti untuk melihat berbagai peluang yang ada guna menciptakan suasana blended learning yang semakin maksimal. 
Seiring perkembangan zaman, khususnya dalam masa pandemi seperti ini, guru perlu menguasai strategi blended learning (Rizkiyah, 2015) agar dapat memberikan pengalaman belajar yang bermakna bagi siswa. Penelitian Mihaela \& Stoicescu (2011) menyatakan bahwa blended learning dapat digunakan sebagai alat untuk memperkuat kompetensi mengajar. Oleh sebab itu, mahasiswa calon guru perlu dipersiapkan dan dibekali mengenai blended learning. Salah satu caranya adalah melalui mata kuliah PSAP (Perencanaan Strategi Asesmen Pembelajaran) Matematika Sekolah Menengah. Ketika mengambil mata kuliah ini, mahasiswa dituntut untuk dapat melaksanakan pengajaran mikro (microteaching) matematika sekolah menengah (SMP atau SMA) secara daring. Pengajaran mikro menyediakan lingkungan yang mendukung mahasiswa calon guru untuk dapat mempraktikkan keterampilan instruksional mereka, menerima umpan balik tentang kinerja mereka, merefleksikan umpan balik tersebut, dan kemudian menggunakan informasi ini untuk meningkatkan pengajaran mereka (Ralph, 2014). Penelitian Bakır (2014) menyatakan bahwa pengajaran mikro memiliki pengaruh yang signifikan terhadap keterampilan mengajar, dan pengaruh tersebut dapat dilihat dalam kegiatan apersepsi, manajemen kelas, manajemen waktu, menyimpulkan pembelajaran, serta dalam melaksanakan komunikasi yang efektif.

Sebelum pengajaran mikro dilaksanakan, mahasiswa perlu membuat Rencana Pelaksanaan Pembelajaran (RPP) yang disusun dengan mempertimbangkan kesesuaian aktivitas yang merupakan kegiatan sinkronus (tatap maya) dan asinkronus (belajar mandiri). Ketika sinkronus, guru dan siswa dapat bertatap maya dan melakukan interaksi langsung pada waktu bersamaan dalam jaringan internet, sementara ketika asinkronus guru dan siswa tidak bertatap maya dan berinteraksi dalam waktu bersamaan (Kusuma, 2020). Mahasiswa dibagi menjadi beberapa kelompok untuk pelaksaan pengajaran mikro. Satu kelompok terdiri dari 5 orang dan mahasiswa bergantian peran sebagai guru. Tujuan pembagian kelompok adalah untuk memudahkan mahasiswa berkoordinasi dan meringankan beban kuota mahasiswa. Mahasiswa diberikan waktu selama 20 menit untuk melaksanakan pembelajaran sinkronus (tatap maya). Pengajaran mikro yang dilaksanakan meliputi kegiatan sinkronus dan asinkronus. Dalam kegiatan sinkronus, mahasiswa guru dilatih untuk dapat berinteraksi dengan siswa secara tatap maya, menekankan konsep-konsep penting, dan mengamati perkembangan siswa secara langsung. Sementara dalam kegiatan asinkronus, mahasiswa guru dilatih untuk dapat memberikan informasi serta arahan secara tepat dan jelas sehingga siswa dapat menerima dan melaksanakan arahan tersebut. Kegiatan pengajaran mikro secara daring diharapkan dapat memberikan pengalaman baru bagi mahasiswa. Mahasiswa dapat merasakan dan mengalami secara langsung mengajar di tengah keterbatasan tidak dapat bertatap muka secara langsung dengan siswanya. Sehingga pada akhirnya mahasiswa siap untuk mengajar di tengah berbagai kondisi yang tidak ideal.

Selama ini penelitian blended learning berfokus kepada melihat bagaimana implementasi blended learning yang dilakukan oleh guru atau dosen terhadap peserta didik pada pembelajaran konten (Quinn \& Aarão, 2020; Wahyudi et al., 2020; Warren et al., 2020). Sementara itu, pada konteks pengajaran mikro secara daring, penelitian yang dilakukan hanya berupa rekaman video pengajaran guru yang dianalisis secara asinkronus (Kusmawan, 2017). Keunikan penelitian ini terletak pada tujuan untuk melihat efektivitas pengajaran mikro yang dilaksanakan oleh mahasiswa guru secara daring dengan menerapkan blended learning yang berupa kombinasi kegiatan sinkronus dan asinkronus, di mana hal tersebut masih jarang ditemukan dalam penelitian selama masa pandemi ini.

\section{METODE PENELITIAN}

Penelitian ini menggunakan metode kualitatif deskriptif. Adapun langkah yang dilakukan dalam penelitian ini meliputi: (1) menganalisis dan menentukan fokus masalah; (2) mencari dan menganalisis sumber bacaan; (3) menyusun instrumen penelitian; (4) mengumpulkan data penelitian; (5) menganalisis data penelitian; dan (6) membuat kesimpulan.

Subjek penelitian meliputi 35 mahasiswa Program Studi Pendidikan Matematika Universitas Pelita Harapan Angkatan 2018. Minat mahasiswa dapat dilihat dari program studi yang dipilih, yang berarti bahwa mahasiswa pendidikan matematika merupakan mahasiswa yang memiliki minat untuk menjadi seorang guru matematika (Delima \& Budianingsih, 2020). Penelitian dilaksanakan pada Semester Ganjil Tahun 
Akademik 2020/2021. Pada semester sebelumnya, yaitu Semester Genap Tahun Akademik 2019/2020, mahasiswa selaku subjek penelitian telah melaksanakan pengajaran mikro untuk pembelajaran Matematika Sekolah Dasar. Sebelum pandemi (Januari 2020-pertengahan Maret 2020) sebagian mahasiswa telah melaksanakan pengajaran mikro di laboratorium pengajaran mikro dimana yang menjadi siswanya adalah sesama mahasiswa di kelas tersebut. Gambar 1 menunjukkan laboratorium pengajaran mikro.
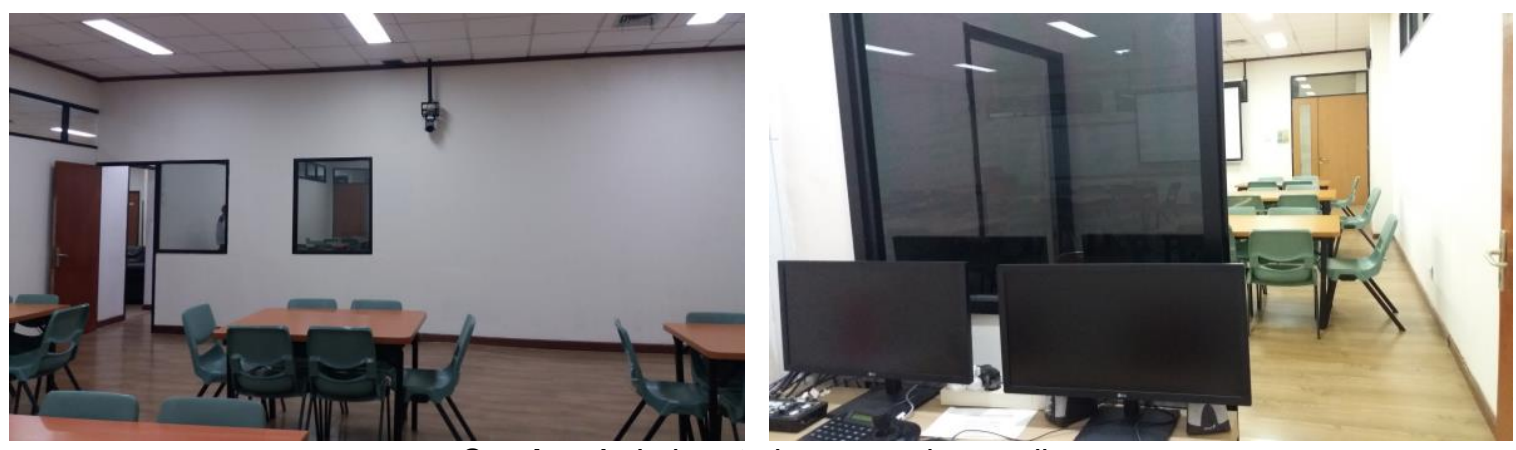

Gambar 1. Laboratorium pengajaran mikro

Gambaran mahasiswa yang sedang melaksanakan pengajaran mikro di laboratorium pengajaran mikro disajikan pada Gambar 2.

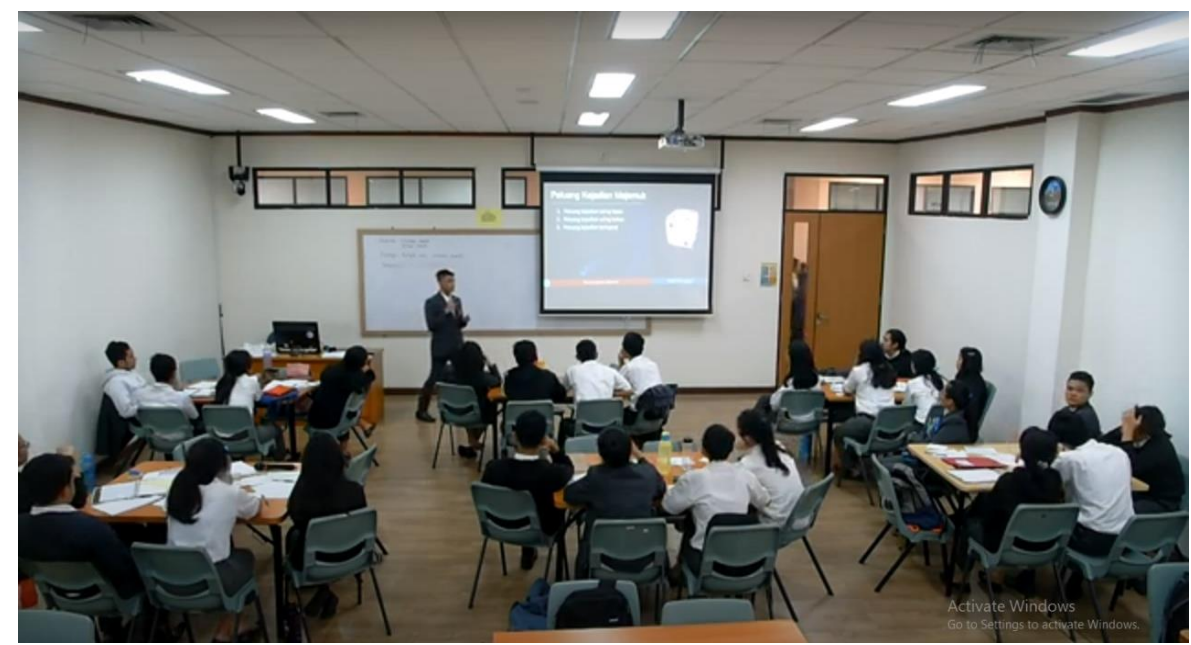

Gambar 2. Praktik pengajaran mikro di laboratorium

Saat pandemi (setelah Maret 2020), sebagian mahasiswa melaksanakan pengajaran mikro dengan merekam pembelajaran tatap muka. Mahasiswa mencari kenalan, keluarga, atau saudara yang ada di sekitar lingkungan tempat tinggal untuk berperan sebagai siswa. Ini berarti, mahasiswa sudah memiliki pengalaman sebelumnya dalam pengajaran mikro secara tatap muka. Oleh karenanya, dengan melaksanakan pengajaran mikro secara blended learning (sinkronus dan asikronus) akan memperkaya pengalaman mengajar mahasiswa.

Instrumen yang digunakan dalam penelitian meliputi: rubrik pengajaran mikro, kuesioner, dan wawancara tertulis mengenai efektivitas pengajaran mikro. Rubrik pengajaran mikro digunakan dosen untuk melihat keterampilan mengajar mahasiswa. Adapun kriteria yang dinilai dalam rubrik meliputi keterampilan: (1) pembukaan/pendahuluan; (2) strategi/metode mengajar; (3) pemahaman konsep; (4) media pembelajaran; (5) manajemen kelas; (6) berbicara; dan (7) penutup. Rubrik pengajaran mikro yang digunakan merupakan rubrik baku skala 4 (Sangat Baik, Baik, Cukup, Kurang) yang digunakan di Fakultas IImu Pendidikan UPH.

Instrumen kuesioner efektivitas pengajaran mikro terdiri dari 10 butir pertanyaan dengan empat skala Likert (Sangat Setuju, Setuju, Tidak Setuju, dan Sangat Tidak Setuju). Kuesioner efektivitas 
pengajaran mikro diberikan kepada mahasiswa melalui fitur "Quiz" di Moodle Mata Kuliah PSAP Matematika Sekolah Menengah. Kuesioner telah diuji validitasnya dan diperoleh nilai korelasi Pearson $r$ pada setiap butir pernyataan melebihi nilai $r$ tabel $=0,344$ yang dapat dilihat pada Tabel 1 . Hal ini berarti setiap pertanyaan valid. Adapun nilai reliabilitas kuesioner secara keseluruhan dihitung menggunakan Cronbach Alpha dan diperoleh hasil $\alpha=0,839$ yang termasuk dalam kategori tinggi.

Tabel 1. Validitas kuesioner

\begin{tabular}{cc}
\hline No. Pertanyaan & Validitas $(\boldsymbol{r})$ \\
\hline 1 & 0,374 \\
2 & 0,391 \\
3 & 0,501 \\
4 & 0,725 \\
5 & 0,500 \\
6 & 0,765 \\
7 & 0,577 \\
8 & 0,349 \\
9 & 0,499 \\
10 & 0,636 \\
\hline
\end{tabular}

Instrumen wawancara tertulis terdiri dari 5 pertanyaan terbuka yang juga diberikan kepada mahasiswa dengan menggunakan fitur "Quiz" di Moodle. Pertanyaan tersebut, yaitu: (1) Apa perbedaan pengajaran mikro sebelum pandemi (offline) dan saat pandemi (online)? Jelaskan; (2) Apakah pelaksanaan pengajaran mikro secara online dapat membantu Anda mempersiapkan diri sebagai seorang guru? Jelaskan; (3) Apakah menurut Anda pelaksanaan microteaching secara online efektif? Jelaskan; (4) Apa hal paling menarik/berkesan yang Anda jumpai selama sesi microteaching? Jelaskan; dan (5) Jika pembelajaran daring masih berlangsung di semester depan, apa saran Anda bagi pembelajaran PSAP Matematika ke depannya, khususnya dalam sesi microteaching? Jelaskan.

Pelaksanaan penelitian dari mulai pertemuan pertama dimulai pada 25 Agustus 2020 dan pertemuan terakhir (pertemuan ke-16) dilaksanakan pada 8 Desember 2020 disajikan pada Tabel 2.

Tabel 2. Time Line penelitian

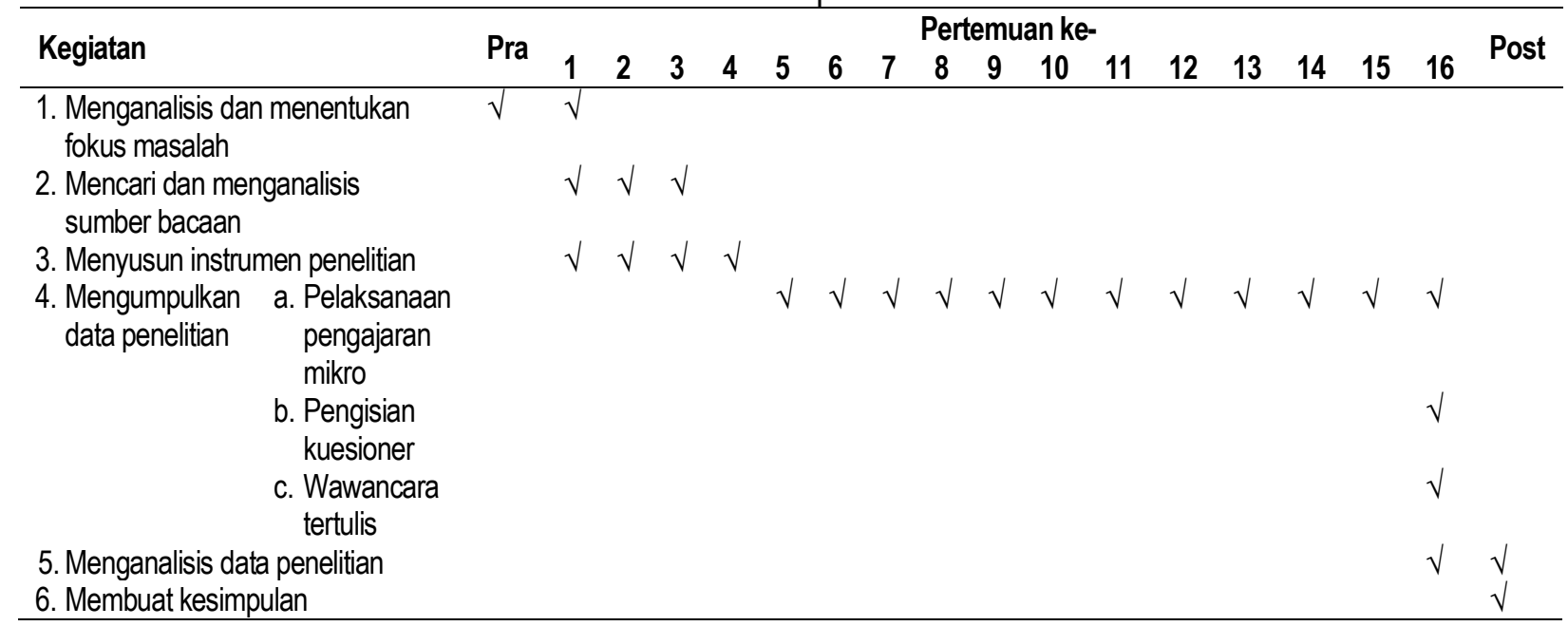

Data dalam penelitian ini diperoleh dari ketiga instrumen yang digunakan. Rubrik pengajaran mikro diisi oleh dosen pengampu (70\%) dan sesama rekan mahasiswa (30\%) setelah menyimak rekaman video pengajaran mikro (Pertemuan 5-16). Kuesioner dan wawancara tertulis disi pada pertemuan terakhir (Pertemuan 16). Setelah data instrumen diperoleh kemudian diolah dan dianalisis. Data kuantitatif diolah dengan bantuan SPSS untuk memperoleh statistik deskriptif, sementara data kualitatif dianalisis dengan menggunakan sistem koding (mengelompokkan persepsi yang sama/mirip). 


\section{HASIL DAN PEMBAHASAN}

Pengajaran mikro memberikan kesempatan bagi mahasiswa guru untuk dapat meningkatkan keterampilan mengajar karena memberikan pengalaman nyata mengajar (Remesh, 2013). Pengajaran mikro menjadi sarana bagi mahasiswa calon guru untuk dapat mempelajari dan memperbaiki keterampilan mengajar sebelum mahasiswa melaksanakan praktek lapangan (Ralph, 2014). Tabel 3 memperlihatkan deskriptif pencapaian mahasiswa dalam pengajaran mikro sesuai dengan rubrik yang telah disusun.

Tabel 3. Deskriptif nilai pengajaran mikro

\begin{tabular}{lc}
\hline & Nilai \\
\hline Rata-rata & 84,69 \\
Variansi & 20,23 \\
Standar Deviasi & 4,50 \\
Minimum & 72,46 \\
Maksimum & 94,39 \\
\hline
\end{tabular}

Berdasarkan Tabel 3, dapat dilihat bahwa pencapaian mahasiswa dalam pengajaran mikro sudah baik. Sekalipun pengajaran mikro dilaksanakan secara blended learning, namun mahasiswa mempersiapkan dan melaksanakan pengajaran mikro dengan semaksimal mungkin. Di akhir pembelajaran PSAP Matematika setelah seluruh mahasiswa menyimak video pengajaran mikro pada hari itu, mahasiswa dan dosen melaksanakan perkuliahan tatap maya untuk memberikan feedback dan evaluasi bersama kepada mahasiswa calon guru yang melaksanakan pengajaran mikro. Kegiatan evaluasi setelah mahasiswa melaksanakan pengajaran mikro membantu mahasiswa untuk berefleksi mengenai kekuatan dan kelemahan mereka. Dengan adanya pandemi covid-19 yang mengubah teknis pembelajaran maka mahasiswapun harus dibekali dan dipersiapkan mengenai bagaimana cara mengajar secara daring dengan lebih efektif. Hal ini berdampak pada pengajaran mikro yang juga dilakukan secara sinkronus tatap maya dan asinkronus belajar mandiri. Pengajaran mikro perdana secara daringpun perlu dievaluasi keefektifannya agar dapat terus diperbaiki sehingga dapat maksimal di dalam memberi bekal kepada mahasiswa calon guru.

Pada pertemuan terakhir perkuliahan, mahasiswa diminta untuk mengisi kuesioner mengenai keefektifan pengajaran mikro secara daring. Secara umum, seluruh mahasiswa setuju bahwa pengajaran mikro secara daring efektif dalam membantu mahasiswa mengembangkan keterampilan mengajar. Tabel 4 menampilkan rerata perolehan skor setiap pertanyaan kuesioner.

Tabel 4. Rerata skor kuesioner

\begin{tabular}{clc}
\hline No & \multicolumn{1}{c}{ Pertanyaan } & Rerata \\
\hline 1 & Saya selalu hadir dalam sesi pengajaran mikro secara online (sinkronus). & 3,69 \\
2 & Penempatan teman sejawat sebagai siswa dinilai cukup efektif. & 3,20 \\
3 & Pengajaran mikro membantu saya mempersiapkan diri untuk mengajar secara online. & 3,74 \\
4 & Saya belajar dari setiap pengajaran mikro yang dilakukan oleh teman sejawat. & 3,69 \\
5 & Sesi pengajaran mikro membuat keterampilan mengajar saya semakin baik. & 3,63 \\
6 & Penggunaan media Zoom atau Ms.Teams dinilai cukup efektif di dalam pengajaran mikro online. & 3,54 \\
7 & Dosen menunjukkan kelebihan dan kelemahan saya setelah praktik pengajaran mikro. & 3,77 \\
8 & Dosen memberikan perbaikan terhadap praktik pengajaran mikro yang telah dilakukan. & 3,80 \\
9 & Teman sejawat menunjukkan kelebihan dan kelemahan saya setelah praktik pengajaran mikro. & 3,60 \\
10 & Penerapan kelompok kecil cukup efektif di dalam pengajaran mikro online. & 3,51 \\
& & Rerata \\
\hline
\end{tabular}

Rerata yang diperoleh dari kesepuluh pertanyaan adalah 3,62. Secara persentase nilai tersebut setara dengan $90,5 \%$. Walaupun dilaksanakan secara daring, esensi dari pengajaran mikro sebagai sarana mengembangkan keterampilan mengajar masih dirasakan oleh mahasiswa calon guru. Ini berarti, pengajaran mikro secara daring (tatap maya) yang dilakukan sudah dirasakan efektif oleh mahasiswa. Dari tabel dapat dilihat bahwa setiap pertanyaan memiliki rerata di atas 3,5 kecuali pertanyaan nomor 2 . 
Pertanyaan yang berkaitan dengan teman sejawat ini memiliki rerata 3,2. Namun jika dilihat dari nilai maksimal 4 maka nilai ini sudah cukup tinggi.

Untuk mendalami hasil kuesioner keefektifan pengajaran mikro secara daring maka akan dilakukan analisis terhadap wawancara tertulis.

Pertanyaan 1: Apa perbedaan pengajaran mikro sebelum pandemi (offline) dan saat pandemi (online)? Jelaskan.

Jika dikelompokkan maka jawaban mahasiswa dapat dibagi ke dalam dua jenis, yaitu teknis dan non teknis. Secara teknis, perbedaan pengajaran mikro saat pandemi dan sebelum pandemi adalah dalam media/tempat: pengajaran mikro sebelum pandemi dilaksanakan di laboratorium pengajaran mikro sementara saat pendemi pengajaran mikro dilaksanakan secara daring menggunakan bantuan platform Zoom dan Microsoft Teams. Dalam kondisi ini, ketersediaan jaringan yang mendukung sangat diperlukan karena berpengaruh terhadap kualitas pengajaran mikro yang dilaksanakan. Ketika terjadi kendala teknis, maka waktu pembelajaran akan terkuras untuk mengurus hal-hal teknis tersebut. Dampak yang ditimbulkan adalah kegiatan pembelajaran menjadi tidak cukup jelas karena suara dapat terputus atau tersendat (delay). Sulitnya jaringan juga menjadi kendala pembelajaran daring secara umum di Indonesia (Hafiz et al., 2020; Kurniati et al., 2021; Rigianti, 2020).

Secara non teknis, perbedaan yang dirasakan berkaitan dengan pengajaran mikro secara daring adalah: guru kurang dapat melihat perkembangan siswa secara afektif, guru tidak dapat melihat perilaku siswa secara langsung, guru perlu usaha ekstra dalam manajemen kelas juga dalam mempersiapkan media ajar. Kondisi tersebut menimbulkan adanya perbedaan pada suasana kelas yang dibangun. Hal ini membuat strategi/pendekatan yang digunakanpun perbeda dan perlu lebih bervariasi serta menarik sehingga siswa dapat tetap terlibat secara aktif selama mengikuti pembelajaran. Guru juga memerlukan usaha ekstra untuk dapat membangun komunikasi efektif dengan siswa. Hal-hal ini juga menjadi kendala yang ditemukan guru-guru ketika melaksanakan pembelajaran daring, yaitu dalam hal penilaian (Hafiz et al., 2020; Kurniati et al., 2021; Rigianti, 2020), pengelolaan pembelajaran (Rigianti, 2020), serta pengawasan (Rahmawati \& Yulianti, 2020; Rigianti, 2020).

\section{Pertanyaan 2: Apakah pelaksanaan pengajaran mikro secara online dapat membantu Anda mempersiapkan diri sebagai seorang guru? Jelaskan.}

Keseluruhan mahasiswa menjawab bahwa pelaksanaan pengajaran mikro secara daring dapat membantu persiapan mereka sebagai seorang guru. Alasannya adalah karena dengan pengajaran mikro, mahasiswa dapat terpacu dan terlatih untuk memanfaatkan teknologi dalam mengajar, mempersiapkan diri menjadi seorang guru yang profesional dalam menghadapi berbagai situasi, melatih berpikir kreatif dalam mempersiapkan dan melaksanakan pembelajaran, serta memperkaya strategi/metode pengajaran. Hal ini sejalan dengan pernyataan Remesh (2013) bahwa keterampilan inti dari pengajaran mikro seperti keterampilan memberikan penjelasan dan penguatan membantu guru pemula untuk mempelajari seni mengajar dengan mudah dan maksimal.

\section{Pertanyaan 3: Apakah menurut Anda pelaksanaan microteaching secara online efektif? Jelaskan.}

Sebagian besar mahasiswa menyatakan bahwa pengajaran mikro secara daring dinilai efektif dilaksanakan di tengah kondisi pandemi seperti saat ini. Hal ini dikarenakan mahasiswa memperoleh pengalaman mengajar yang bervariasi dari masa sebelumnya saat masih berupa perkuliahan tatap muka. Hal ini selaras dengan hasil penelitian sebelumnya bahwa dalam pembelajaran daring, kreativitas guru sangat diperlukan agar siswa mampu mengikuti proses pembelajaran dengan baik (Huzaimah \& Risma, 2021; Rahmawati \& Yulianti, 2020; Suhendra et al., 2021). Dengan kegiatan pengajaran mikro, mahasiswa semakin diperkaya dengan contoh pembelajaran yang beragam yang disajkan oleh semua mahasiswa. Sebagian besar mahasiswa menyatakan bahwa pengajaran mikro secara daring dinilai efektif dilaksanakan di tengah kondisi pandemi seperti saat ini. Hal ini dikarenakan mahasiswa memperoleh pengalaman mengajar yang bervariasi dari masa sebelumnya saat masih berupa perkuliahan tatap muka. Hal ini selaras dengan hasil penelitian bahwa dalam pembelajaran daring, kreativitas guru sangat diperlukan agar siswa mampu mengikuti proses pembelajaran dengan baik. Hal ini selaras dengan hasil penelitian dimana akibat 
beralihnya pembelajaran ke tatap maya, guru menjadi kaya akan pengalaman baru, dan mencoba hal-hal baru. Melalui pemanfaatan teknologi dalam pembelajaran akan memberi pengaruh terhadap proses dan hasil belajar siswa (Zakiah \& Fajriadi, 2020). Namun beberapa mahasiswa menjawab bahwa pelaksanaan pengajaran mikro secara daring kurang efektif karena kendala jaringan yang menyebabkan pembelajaran menjadi sedikit terganggu.

Pertanyaan 4: Apa hal paling menarik/berkesan yang Anda jumpai selama sesi microteaching? Jelaskan.

Berbagai jawaban mengenai pertanyaan ini muncul. Bagi beberapa mahasiswa, hal yang menarik adalah ketika menyimak video pengajaran mikro dari rekan sejawat dan ketika memberikan komentar sebagai umpan balik. Mahasiswa merasa dapat belajar dari video pengajaran mikro yang dilakukan oleh rekan sejawat. Hal positif lainnya adalah video pengajaran mikro tersebut dapat memperlengkapi mahasiswa untuk mengajar lebih baik. Saran serta masukan yang bersifat membangun dari dosen dan rekan sejawat pun sangat berguna bagi mahasiswa untuk dapat terus meningkatkan kualitas pengajaran. Selain itu, melalui video pengajaran mikro rekannya, mahasiswa kembali diingatkan mengenai materi yang terlupakan yang pernah dipelajari sewaktu duduk di bangku sekolah. Sejalan dengan hal ini, Remesh (2013) menyatakan bahwa pengajaran mikro dapat digunakan secara efektif untuk mempelajari keterampilan baru dan memperkuat serta mengembangkan keterampilan yang sudah ada.

Hal lain yang berkesan bagi mahasiswa adalah pada tahap persiapan, di mana merupakan tahap yang cukup menantang. Pada tahap ini mahasiswa ditantang untuk dapat mempersiapkan pembelajaran yang dapat memotivasi serta menarik bagi siswa namun tidak mengesampingkan konsep/materi yang perlu disampaikan. Ada pula mahasiswa yang menyatakan bahwa hal yang paling berkesan baginya adalah ketika ia menceritakan kebesaran Tuhan kepada siswa melalui kegiatan pembelajaran. Pembelajaran tidak hanya berfokus pada aspek intelektual siswa, namun juga perlu memperkenalkan Tuhan (Bongga \& Listiani, 2020).

Selain itu, hal menarik yang juga dikemukakan adalah walaupun melaksanakan pembelajaran di tengah kendala jaringan namun siswa (responden) masih bersemangat sehingga mahasiswa calon guru pun menjadi ingin memberikan pembelajaran yang terbaik. Ada pula mahasiswa yang merasa bahwa karena dalam pengajaran mikro secara daring ini guru juga dilatih untuk cepat tanggap dan memberikan respon yang benar maka hal ini menjadikan pengajaran mikro secara daring sangat menarik.

Pertanyaan 5: Jika pembelajaran daring masih berlangsung di semester depan, apa saran Anda bagi pembelajaran PSAP Matematika ke depannya, khususnya dalam sesi microteaching? Jelaskan.

Sebagian besar mahasiswa menyatakan bahwa pengajaran mikro secara daring sejauh ini sudah baik dan dapat mendukung mahasiswa mengembangkan kompetensi mengajar. Terdapat beberapa saran yang dikemukakan, yaitu mengenai jumlah anggota kelompok yang perlu diperbanyak; pembagian urutan pengajaran mikro perlu disesuaikan agar dalam satu minggu cukup satu mahasiswa dalam satu kelompok yang melaksanakan pengajaran mikro. Saran lainnya adalah agar mahasiswa dilarang mengedit video pengajaran mikro (memotong durasi waktu) agar terlihat bagaimana kesiapannya. Jika memungkinkan bisa menggunakan siswa sungguhan sebagai siswa dalam pengajaran mikro secara daring. Pengajaran mikro merupakan sarana bagi mahasiswa untuk belajar dan bertumbuh sehingga memang idealnya perlu diusahakan dalam lingkungan sealami mungkin (Pinasti, 2008). Hal ini bertujuan agar mahasiswa dapat belajar dan mengalami proses belajar mengajar dan interaksi dengan siswa secara langsung.

\section{KESIMPULAN}

Pengajaran mikro yang dilaksanakan secara daring dengan menerapkan blended learning (sinkronus dan asinkronus) dalam masa pandemi dinilai masih efektif dalam membantu mahasiswa mengembangkan kompetensi mengajarnya. Walaupun ada beberapa mahasiswa yang mengalami kendala dalam jaringan namun secara keseluruhan setiap mahasiswa memperoleh pengalaman baru dan belajar hal baru. Pengajaran mikro secara daring dapat mempertajam kompetensi mahasiswa calon guru dalam 
mempersiapkan pembelajaran, menyusun strategi dan media yang tepat, menyampaikan materi, memberikan arahan kepada siswa, serta membangun komunikasi dalam konteks blended learning.

\section{REKOMENDASI}

Penelitian ini dapat dilanjutkan untuk melihat kompetensi mahasiswa calon guru dalam mengajar khususnya ketika melaksanakan Program Pengenalan Lapangan (PPL) dan Pendidikan Profesi Guru (PPG).

\section{UCAPAN TERIMAKASIH}

Ucapan terima kasih disampaikan kepada Program Studi Pendidikan Matematika Fakultas IImu Pendidikan Universitas Pelita Harapan.

\section{DAFTAR PUSTAKA}

Bakır, S. (2014). The effect of microteaching on the teaching skills of pre-service science teachers. Journal of Baltic Science Education, 13(6), 789-801.

Bakker, A., \& Wagner, D. (2020). Pandemic : lessons for today and tomorrow?. Educational Studies in Mathematics, 104(1), 1-4. https://doi.org/10.1007/s10649-020-09946-3

Bongga, S. D. V. Van, \& Listiani, T. (2020). Implementasi strategi integrasi iman dan pembelajaran john w. taylor dalam pembelajaran matematika pada materi bilangan. JOHME: Journal of Holistic Mathematics Education, 4(1), 45-63. https://doi.org/https://dx.doi.org/10.19166/johme.v4i1.1987

Delima, N., \& Budianingsih, Y. (2020). Gaya belajar dan mathematics self-concept terhadap minat akademik mahasiswa. Teorema: Teori dan Riset Matematika, 5(1), 1-8. https://doi.org/http://dx.doi.org/10.25157/teorema.v5i1.3296

Dhawan, S. (2020). Online Learning: A Panacea in the time of covid-19 crisis. Journal of Educational Technology Systems, 49(1), 5-22. https://doi.org/https://doi.org/10.1177/0047239520934018

Fahmi, M. H. (2020). Komunikasi synchronous dan asynchronous dalam e-learning pada masa pandemic covid-19. Jurnal Nomosleca, 6(2), 68-76.

Hafiz, M., Desniarti, \& Anisa, Y. (2020). Pembelajaran daring yang dihadapi guru sekolah menengah atas. Jurnal IImu Pendidikan, 1(2), 103-106.

Herliana, F., Halim, A., Farhan, A., \& Elisa. (2020). Identification of lecturer difficulties in implementing of blended learning in the covid-19 era. Asian Journal of Science Education, 2(2), 106-113.

Huzaimah, P. Z., \& Risma, A. (2021). Hambatan yang dialami siswa dalam pembelajaran daring matematika pada masa pandemi covid-19. Jurnal Cendekia: Jurnal Pendidikan Matematika, 05(01), 533-541.

Ismawati, D., \& Prasetyo, I. (2020). Efektivitas pembelajaran menggunakan video zoom cloud meeting pada anak usia dini era pandemi covid-19. Jurnal Obsesi: Jurnal Pendidikan Anak Usia Dini, 5(1), 665-675. https://doi.org/10.31004/obsesi.v5i1.671

Jou, M., Lin, Y. T., \& Wu, D. W. (2016). Effect of a blended learning environment on student critical thinking and knowledge transformation. Interactive Learning Environments, 24(6), 1131-1147. https://doi.org/10.1080/10494820.2014.961485 
Kurniati, T., Yusup, I. R., Hermawati, A. S., \& Kusumahwardani, D. (2021). Respon guru terhadap kendala proses pembelajaran biologi di masa pandemi covid-19. Jurnal Educatio FKIP UNMA, 7(1), 40-46. https://doi.org/10.31949/educatio.v7i1.765

Kusmawan, U. (2017). Online microteaching: a multifaceted approach to teacher professional development. Journal of Interactive Online Learning, 15(1), 42-56.

Kusuma, D. A. (2020). Dampak penerapan pembelajaran daring terhadap kemandirian belajar (selfregulated learning) mahasiswa pada mata kuliah geometri selama pembelajaran jarak jauh di masa pandemi covid-19. Teorema: Teori dan Riset Matematika, 5(2), 169-175. https://doi.org/http://dx.doi.org/10.25157/teorema.v5i2.3504

Manurung, G. N., Manurung, K., Mertosono, S. R., \& Kamaruddin, A. (2020). Perceptions of EFL learners in the implementation of blended learning post-natural disaster at a university in Indonesia. Theory and Practice in Language Studies, 10(8), 959-968. https://doi.org/http://dx.doi.org/10.17507/tpls.1008.15

Mihaela, F., \& Stoicescu, D. (2011). Using blended learning as a tool to strengthen teaching competences. Procedia Computer Science, 3, 1527-1531. https://doi.org/10.1016/j.procs.2011.01.043

Monica, J., \& Fitriawati, D. (2020). Efektivitas penggunaan aplikasi zoom sebagai media pembelajaran online pada mahasiswa saat pandemi covid-19. Jurnal Communio: Jurnal Jurusan IImu Komunikasi, 9(2), 1630-1640. https://doi.org/10.35508/jikom.v9i2.2416

Muhazir, A., \& Retnawati, H. (2020). The teachers' obstacles in implementing technology in mathematics learning classes in the digital era. Journal of Physics: Conference Series, 1511(2020), 1-11. https://doi.org/10.1088/1742-6596/1511/1/012022

Nugroho, W. (2021). Kepuasan siswa terhadap pembelajaran daring menggunakan microsoft teams dan video youtube pada materi program linier student satisfaction to online learning using microsoft. THEOREMS (The Original Research of Mathematics), 5(2), 2-11.

Pinasti, I. S. (2008). Efektivitas real microteaching pada program ppl I (microteaching) di program studi pendidikan sosiologi fise uny. Dimensia, 2(2), 11-19.

Porter, W. W., Graham, C. R., Spring, K. A., \& Welch, K. R. (2014). Blended learning in higher education: Institutional adoption and implementation. Computers and Education, 75, 185-195. https://doi.org/10.1016/j.compedu.2014.02.011

Quinn, D., \& Aarão, J. (2020). Blended learning in first year engineering mathematics. ZDM Mathematics Education, 52(5), 927-941. https://doi.org/10.1007/s11858-020-01160-y

Rahmawati, I. Y., \& Yulianti, B. (2020). Kreativitas guru dalam proses pembelajaran ditinjau dari penggunaan metode pembelajaran jarak jauh di tengah wabah. 5(1), 27-39.

Ralph, E. G. (2014). The effectiveness of microteaching: five years' findings. International Journal of Humanities Social Sciences and Education (IJHSSE), 1(7), 17-28. 
Rasheed, R. A., Kamsin, A., \& Abdullah, N. A. (2020). Challenges in the online component of blended learning: A systematic review. Computers and Education, 144(2020), 1-17. https://doi.org/10.1016/j.compedu.2019.103701

Remesh, A. (2013). Microteaching, an efficient technique for learning effective teaching. Journal of Research in Medical Sciences: The Official Journal of Isfahan University of Medical Sciences, 18(2), 158-163. https://pubmed.ncbi.nlm.nih.gov/23914219

Rigianti, H. A. (2020). Kendala pembelajaran daring guru sekolah dasar di kabupaten banjarnegara. Elementary School, 7(2), 297-302.

Rizkiyah, A. (2015). Penerapan Blended learning untuk meningkatkan hasil belajar siswa pada mata pelajaran ilmu bangunan di kelas X TGB SMK Negeri 7 Surabaya. Jurnal Kajian Pendidikan Teknik Bangunan, 1(1), 40-49.

Suhendra, Nurbaeti, D., \& Gustiawati, S. (2021). Pengaruh kreativitas guru dalam pembelajaran daring terhadap hasil belajar siswa pada mata pelajaran pendidikan agama islam. Edukatif: Jurnal IImu Pendidikan, 3(4), 1409-1417. https://edukatif.org/index.php/edukatif/article/view/568

Wahyudi, W., Waluya, S. B., Suyitno, H., \& Isnarto, I. (2020). The impact of 3CM model within blended learning to enhance students' creative thinking ability. Journal of Technology and Science Education, 10(1), 32-46. https://doi.org/10.3926/jotse.588

Warren, L., Reilly, D., Herdan, A., \& Lin, Y. (2020). Self-efficacy, performance and the role of blended learning. Journal of Applied Research in Higher Education, 13(1), 98-111. https://doi.org/10.1108/JARHE-08-2019-0210

Wichadee, S. (2017). A Development of the blended learning model using edmodo for maximizing students' oral proficiency and motivation. International Journal of Emerging Technologies in Learning (IJET), 12(2), 137-154. https://doi.org/10.3991/ijet.v12i02.6324

Woltering, V., Herrler, A., Spitzer, K., \& Spreckelsen, C. (2009). Blended learning positively affects students' satisfaction and the role of the tutor in the problem-based learning process: Results of a mixed-method evaluation. Advances in Health Sciences Education, 14(5), 725-738. https://doi.org/10.1007/s10459-009-9154-6

Yulyani, R. D. (2020). Pengaruh media pembelajaran google classroom, fasilitas pembelajaran dan minat belajar mahasiswa terhadap motivasi belajar daring selama pandemi covid-19. EdHumanistics: Jurnal IImu Pendidikan, 5(2), 703-714. https://doi.org/10.33752/edhumanistics.v5i2.1071

Zakiah, N. E., \& Fajriadi, D. (2020). Hybrid-PjBL: Creative thinking skills and self-regulated learning of preservice teachers. J. Phys.: Conf. Ser. 1521 032072. doi:10.1088/1742-6596/1521/3/032072 